\title{
Foraging partitioning between giant petrels Macronectes spp. and its relationship with breeding population changes at Bird Island, South Georgia
}

\author{
Jacob González-Solís*, John P. Croxall, Andy G. Wood \\ British Antarctic Survey, Natural Environment Research Council, High Cross, Madingley Road, Cambridge CB3 OET, \\ United Kingdom
}

\begin{abstract}
We satellite-tracked the foraging trips of males and females of the 2 sibling species of giant petrels, Macronectes halli and M. giganteus, breeding sympatrically at Bird Island (South Georgia, Antarctica), during the incubation period (November-December). Size of the activity range in addition to speed and distance covered on foraging trips were similar between the species, but were lower for males than for females in both species. Sex-specific differences agree with previous observations on diets and on attendance at seal carcasses, suggesting that females mainly forage at sea, whereas males mainly scavenge on the coast. Overall, however, the foraging ecology of both species seems very similar. Interspecific and intersexual competition may be reduced by the limited overlap in the at-sea range, with southern giant petrels foraging further south than did northern giant petrels, and females further west than males, suggesting some spatial partitioning in foraging areas. Male northern giant petrels foraged almost exclusively on the South Georgia coast; their strong dependence during the brooding and chick-rearing period on Antarctic fur seals, whose population has increased exponentially in recent years, may be reflected in the recent population increase of northern giant petrels at South Georgia. Foraging areas of giant petrels overlapped extensively with longline fishery distribution, highlighting their susceptibility to being caught on longline hooks. Females were at higher risk during the study period since they made longer trips and foraged further west than males, into areas where local longline fisheries are more active.
\end{abstract}

KEY WORDS: Spatial segregation - Activity range overlap - Satellite tracking - Kernel analysis . Longline fishery $\cdot$ Seabird-fisheries interactions

\section{INTRODUCTION}

Many studies on community organisation have examined the extent of overlap of some niche dimensions, such as macrohabitat, microhabitat, prey type and size, time of day and seasonality of activity (Schoener 1974). Seabird communities are presently believed to be one of the most evident examples of trophic resource partitioning (Ashmole \& Ashmole 1967, Croxall \& Prince 1980, Diamond 1983, Weimers-

*Present address: Dept Biologia Animal (Vertebrats), Universitat de Barcelona, Av. Diagonal 645, 08028 Barcelona, Spain.E-mail: jacob@porthos.bio.ub.es kirch et al. 1986, Ridoux 1994, Croxall et al. 1997, Spear \& Ainley 1998). Segregation of the spatial component of trophic niches by observation of seabirds at sea has been studied (e.g. Weimerskirch et al. 1988, Ballance et al. 1997), but is complicated by the lack of knowledge of the status and the population of origin of the birds observed. In the last decade, satellite-tracking studies have allowed new insight into the spatial component of trophic niches of seabirds, complementing and extending observational studies. Movements and foraging areas of birds of known status and population can now be recorded, so that the nature of spatial and temporal overlaps between species living sympatrically can be evaluated accurately and objectively 
(e.g. Waugh et al. 1999, Wood et al. 2000). Questions requiring a knowledge of detailed aspects of foraging ecology, such as the precise locations of feeding grounds (e.g. Weimerskirch et al. 1994, Rodhouse et al. 1996, Prince et al. 1998) and sexual differences in foraging ecology (Prince et al. 1992, Weimerskirch 1995, Weimerskirch et al. 1997a, González-Solís et al. 2000), can now be addressed.

Satellite-tracked foraging ranges also contribute substantially to studying spatial and temporal overlaps with fisheries (e.g. Croxall \& Prince 1996, Weimerskirch et al. 1997b, Brothers et al. 1998). For giant petrels Macronectes spp., a particular concern is their relationship with Southern Ocean longline fisheries. Longline fisheries are suspected to be the main cause of population decreases of some seabird species (e.g. Croxall et al. 1990, de la Mare \& Kerry 1994, Weimerskirch et al. 1997b, 1999), but giant petrels, whose ship-following habits make them particularly susceptible, have been little studied in this regard.

Identification of mechanisms for reducing interspecies competition between the northern Macronectes halli and southern $M$. giganteus giant petrel species has been particularly elusive. The 2 giant petrel species fulfil all criteria to predict potential interspecific competition for resources: (1) They are closely related and so similar morphologically that until recently they were considered conspecific (Bourne \& Warham 1966). Indeed, intersexual differences in size are greater than interspecific ones, with males being between 20 and $30 \%$ heavier and between 5 and $15 \%$ larger than females (Table 1). (2) Although southern giant petrels breed further south (on the Antarctic Peninsula and at a very few sites on the Antarctic Continent), and further north (in Patagonia, Gough Island and Chatham Islands) than do northern giant petrels, both species coexist at least at several sub-Antarctic islands near the Antarctic Polar front (APF), including South Georgia (Warham 1990). Indeed, they often breed close together, sometimes intermingled and small-scale hybridisation is known, with some successful interbreeding recorded at Marion Island (Burger 1978), Macquarie Island (Johnstone 1978) and South Georgia (Hunter 1983a). (3) Despite extensive study of potential ecological differences, only 1 major difference, that of a $6 \mathrm{wk}$ difference in the timing of breeding, has been identified (Hunter 1987). Indeed, studies on diet composition suggest a substantial overlap in resource utilisation (Hunter 1983b).

Despite the potential suitability of giant petrels for satellite-tracking studies and the success of the initial pilot studies (Parmelee et al. 1985, Strikwerda et al. 1986), the delimitation of foraging ranges through such studies has not yet been undertaken. In addition to contributing to the understanding of species isolating mechanisms in seabirds in general, and giant petrels in particular, such information may be relevant to current concerns about population decreases in giant petrels (Rootes 1988, Jouventin \& Weimerskirch 1990, Woehler \& Johnston 1991, SCAR 1992, Woehler \& Croxall 1997). Thus, our aims in this study were: (1) to characterise the foraging areas of both sexes during the incubation period in order to assess spatial and ecological segregation at this time; and (2) to interpret our results in terms of factors potentially affecting population changes at South Georgia.

\section{METHODS}

Fieldwork was undertaken at Bird Island, South Georgia $\left(54^{\circ} 03^{\prime} \mathrm{S}, 38^{\circ} 36^{\prime} \mathrm{W}\right)$ between 1 November and 31 December 1998. We deployed eleven $30 \mathrm{~g}$ Platform Terminal Transmitters (PTTs) from Microwave, Columbia, Maryland, USA, and $10 \mathrm{~g}$ radio transmitters on 28 breeding adult northern and southern giant petrels. At Bird Island, the mean incubation period of the northern giant petrel Macronectes halli is from 20 September to 10 December whereas for the southern giant petrel $M$. giganteus it extends from 30 October to 20 January. The satellite transmitters were deployed during the incubation period of each species, particularly when incubation periods of both species overlapped, that is between 1 November and 10 December. We tracked only 1 foraging trip per bird to ensure independence among trips. Overall, we deployed satellite 
transmitters on 17 foraging trips (8 females and 9 males) by 17 northern giant petrels and 11 ( 5 females and 6 males) by 11 southern giant petrels. We caught the birds on the nest, attached the PTT and returned the bird to the nest. To minimise nest desertion after deployment, the bird was placed in a cage over the nest. The cage $(135 \times 84 \times 55 \mathrm{~cm})$ was made from wooden posts and $5 \times 5 \mathrm{~cm}$ plastic mesh. Birds usually calmed down within 1 min of release and proceeded with incubation. Afterwards, the cage was removed without any obvious disturbance to the bird. By using this method, we did not record any desertion in relation to the deployment of the PTT. We attached the PTTs to the mid-dorsal mantle feathers using Tesa ${ }^{\circledR}$ tape (Wilson \& Wilson 1989). All birds equipped with PTTs were also provided with a radio transmitter. We installed an antenna in the middle of the breeding area, on the top of a hill, whence we could clearly receive signals from the deployed radio transmitters. In this way, accurate times of departures and arrivals of foraging trips from the breeding area could be obtained. The female-male ratio of culmen length ranges from 0.86 to 0.87 in 4 localities (Hunter 1987) and culmen length range does not overlap between sexes (Hunter 1984a, Table 1). Thus, we sexed study birds of both species by culmen length measurement. We confirmed the assigned sex with reference to the sex of its partner; there were no instances of misassignment.

Data on the position of tracked birds were obtained from the ARGOS system. Initial data validation involved calculating velocities between successive satellite uplinks (ARGOS class A, B, Z and from 0 to 3), and rejecting those where the velocity exceeded a threshold of $30 \mathrm{~m} \mathrm{~s}^{-1}$, and where a manual inspection of the data indicated an unlikely movement away from and back to the normal track as defined by the preceding and following uplinks. This can remove up to $15 \%$ of uplinks per trip, all of which are the low quality, unclassifiable type according to the ARGOS system (class A, B, Z). Mean velocities for each trip were estimated by averaging the velocities between validated locations. Kernel analysis to characterise spatial distribution followed Wood et al. (2000). Validated positions from the same trip were not truly independent, but it should be noted that De Solla et al. (1999) showed that assessing ranges using kernel density procedures does not require serial independence of data. We defined 3 categories of activity ranges as the areas encompassing 50,30 and $10 \%$ of validated locations. Overlap was calculated for each category but also for each species, that is, the percentage of the activity range of northern giant petrel which overlapped that of southern giant petrel, and the percentage of the activity range of southern giant petrel which overlapped that of northern giant petrel. Calculation of overlap is needed for each species because any given area of overlap will represent a different percentage for each species depending on the total area of that species' activity range. Each overlap value was calculated by averaging the overlap value obtained at 2 density levels, one defined by the southern giant petrel area and the other defined by the northern giant petrel area.

Results are shown as medians unless otherwise indicated. All tests were 2-tailed and the significance level was set to $\mathrm{p}<0.05$.

\section{RESULTS}

Locations (validated as described above) received for all trips are shown in relation to sex and species in Fig. 1. The respective activity ranges derived from kernel analyses on validated locations in relation to gender and species are shown in Fig. 2. There is a clear concentration of validated locations from male northern giant petrels around South Georgia, whereas the main foraging area of male southern giant petrels was south and east of South Georgia. Females from both species tended to forage at sea, far from South Georgia, mainly to the west.

Mean values of latitude and longitude of northern and southern giant petrel foraging trips during the incubation period, and the maximum limits of these trips, are shown in Table 2. Each species of giant petrel exploited largely separate areas, with southern giant petrels foraging significantly farther south than northern giant petrels (2-way ANOVA of northern and southern giant petrel foraging trips; mean latitude, sex: $F_{1,24}=0.40, \mathrm{p}=0.53$, species: $F_{1,24}=8.66, \mathrm{p}<0.01$;

Table 2. Mean values $( \pm \mathrm{SD})$ of mean latitude $\left({ }^{\circ} \mathrm{S}\right)$ and longitude $\left({ }^{\circ} \mathrm{W}\right)$ of northern and southern giant petrel foraging trips during the incubation period, and of the maximum limits of these trips. $n=$ number of trips. Significant differences between species or sexes for each row are indicated with different letters (2-way ANOVA)

\begin{tabular}{|c|c|c|c|c|}
\hline & \multicolumn{2}{|c|}{ Northern qiant petrels } & \multicolumn{2}{|c|}{ Southern giant petrels } \\
\hline & $\begin{array}{l}\text { Males } \\
(\mathrm{n}=9)\end{array}$ & $\begin{array}{l}\text { Females } \\
(\mathrm{n}=8)\end{array}$ & $\begin{array}{l}\text { Males } \\
(\mathrm{n}=6)\end{array}$ & $\begin{array}{l}\text { Females } \\
(\mathrm{n}=5)\end{array}$ \\
\hline Mean latitude & $53.1 \pm 3.5^{\mathrm{a}}$ & $53.4 \pm 1.5^{\mathrm{a}}$ & $56.8 \pm 2.0^{\mathrm{b}}$ & $55.3 \pm 1.2^{\mathrm{b}}$ \\
\hline Mean longitude & $38.0 \pm 3.9$ & $44.7 \pm 11.6$ & $32.5 \pm 9.4$ & $36.7 \pm 13.3$ \\
\hline Maximum south & $55.4 \pm 1.4^{\mathrm{a}}$ & $56.6 \pm 2.0^{\mathrm{a}}$ & $60.0 \pm 3.1^{\mathrm{b}}$ & $59.7 \pm 1.9^{b}$ \\
\hline Maximum north & $51.2 \pm 5.8$ & $50.6 \pm 2.6$ & $53.6 \pm 0.5$ & $50.4 \pm 4.0$ \\
\hline Maximum west & $43.2 \pm 9.5^{\mathrm{a}}$ & $53.7 \pm 12.7^{\mathrm{b}}$ & $39.5 \pm 1.6^{\mathrm{a}}$ & $47.4 \pm 13.0^{\mathrm{b}}$ \\
\hline Maximum east & $33.6 \pm 3.6$ & $33.5 \pm 7.0$ & $28.5 \pm 12.9$ & $25.6 \pm 11.5$ \\
\hline
\end{tabular}



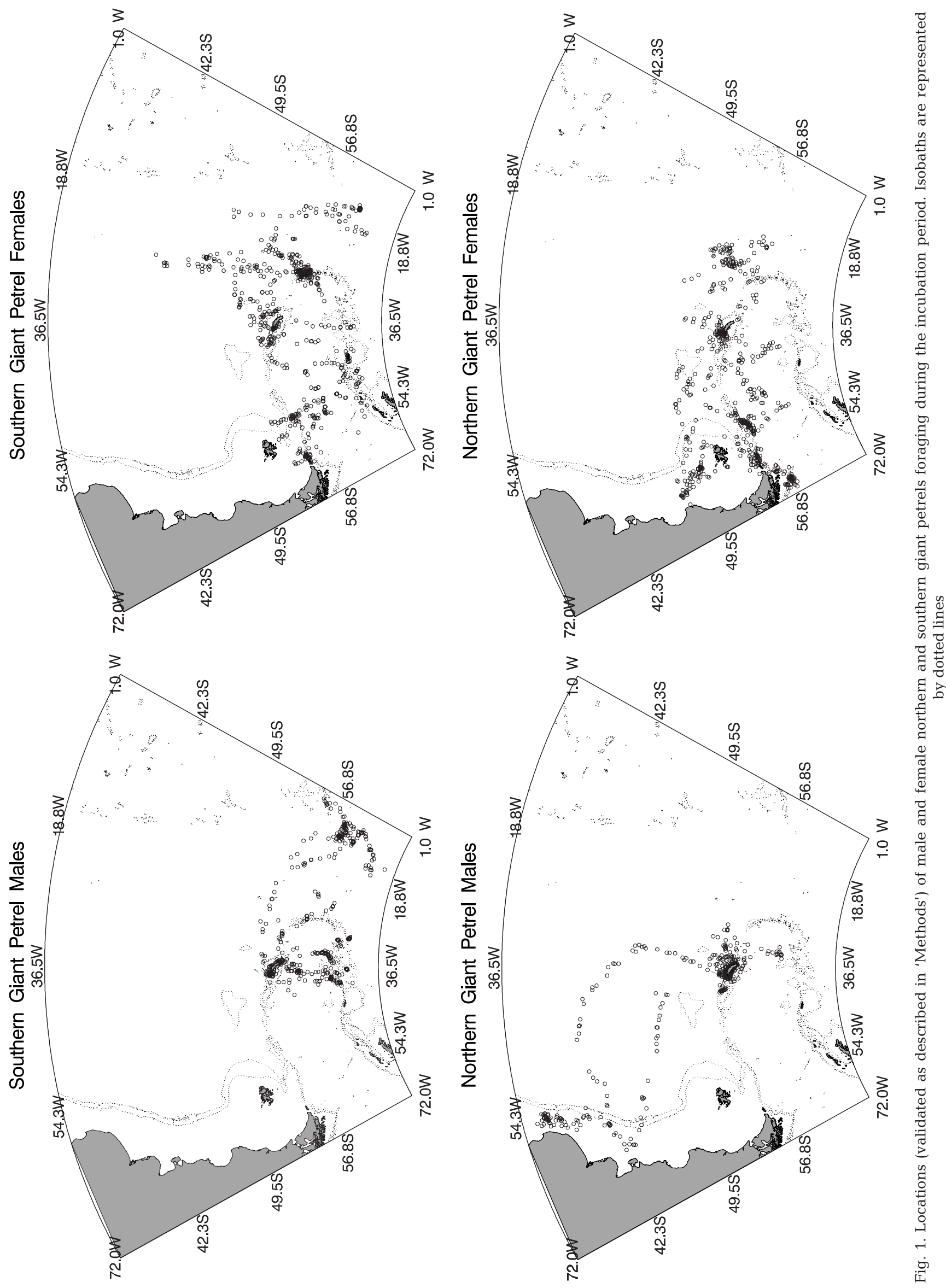

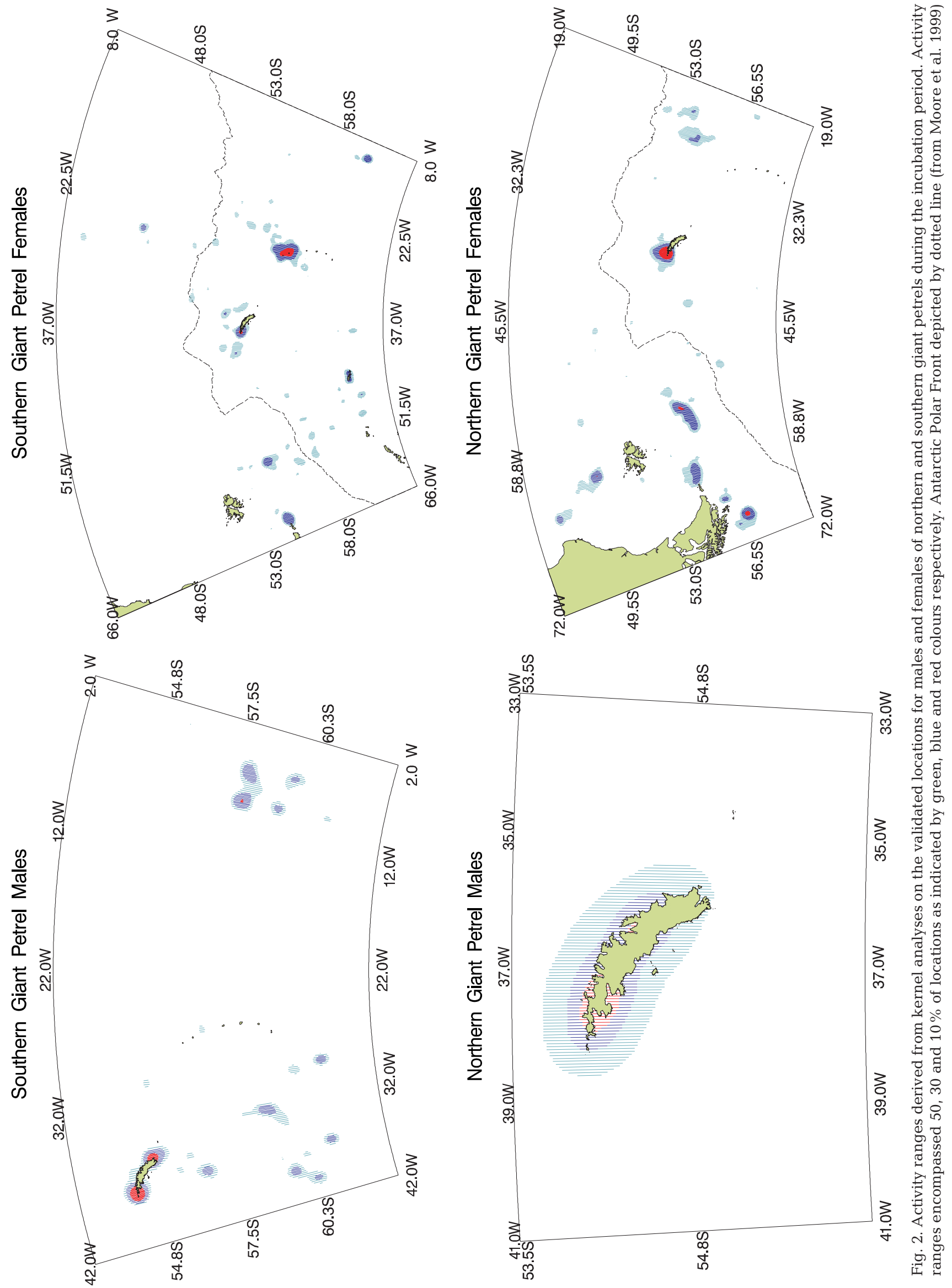
maximum south, sex: $F_{1,24}=0.20, \mathrm{p}=0.66$, species: $F_{1,24}=22.03, \mathrm{p}<0.001$; maximum north, sex: $F_{1,24}=$ $1.61, \mathrm{p}=0.22$, species: $F_{1,24}=0.51, \mathrm{p}=0.48$; interactions not significant). Likewise, there was a spatial segregation in longitude between northern giant petrel females, northern giant petrel males, southern giant petrel females and southern giant petrel males, from west to east, respectively (Table 2). In particular the ranges of female giant petrels extended significantly further west than did those of males (Table 2; 2-way ANOVA of northern and southern giant petrel foraging trips; mean longitude, sex: $F_{1,24}=2.16, \mathrm{p}=0.15$, species: $F_{1,24}=3.27, \mathrm{p}=0.08$; maximum west, sex: $F_{1,24}=5.33, \mathrm{p}<0.05$, species: $F_{1,24}=1.60, \mathrm{p}=0.22$; $\max -$ imum east, sex: $F_{1,24}=0.20, \mathrm{p}=0.66$, species: $F_{1,24}=$ $3,70, \mathrm{p}=0.07$; interactions not significant).

The sizes of activity ranges, as expressed by total area encompassed by 50,30 and $10 \%$ of validated locations, are presented in Table 3 in relation to sex and species. The total size of the areas of activity of northern giant petrel males was, on average, about $18 \%$ that of females. The total size of the comparable areas of activity of southern giant petrel males was, on average, about $68 \%$ that of females. The size of the activity ranges of northern giant petrels was, on average, $29 \%$ that of southern giant petrels. Females of both species showed a very similar size of activity range whereas that of northern giant petrel males was, on average, $28 \%$ that of southern giant petrel males. Thus, the interspecific difference in the size of the activity range arose mainly from the smaller size of the activity range of male northern compared to male southern giant petrels.

To measure the degree of overlap of the activity range between northern and southern giant petrels we

Table 3. Sizes and interspecific overlaps of the activity ranges of northern and southern giant petrels. The total areas encompassed by 50,30 and $10 \%$ of locations and differences between sexes and species are shown. NGP: northern giant petrel; SGP: southern giant petrel

\begin{tabular}{|c|c|c|c|c|}
\hline & \multicolumn{3}{|c|}{ Locations encompassed } & \multirow[t]{2}{*}{ Mean } \\
\hline & $50 \%$ & $30 \%$ & $10 \%$ & \\
\hline \multicolumn{5}{|c|}{ Size of activity range $\left(\mathrm{km}^{2}\right)$} \\
\hline Northern giant petrel & 97.4 & 17.1 & 3.4 & \\
\hline Males & 17.4 & 7.1 & 2.0 & \\
\hline Females & 151.4 & 49.3 & 6.9 & \\
\hline Male to female area (\%) & 11 & 14 & 29 & 18 \\
\hline Southern giant petrel & 214.4 & 63.2 & 8.0 & \\
\hline Males & 81.2 & 30.1 & 4.9 & \\
\hline Females & 153.3 & 43.8 & 5.9 & \\
\hline Male to female area (\%) & 53 & 69 & 83 & 68 \\
\hline NGP to SGP area (\%) & 21 & 24 & 41 & 29 \\
\hline \multicolumn{5}{|c|}{ Overlap of activity range (\%) } \\
\hline NGP with SGP (\%) & 36 & 29 & 10 & 25 \\
\hline SGP with NGP (\%) & 28 & 37 & 22 & 29 \\
\hline
\end{tabular}

performed an overlap analysis on each of the areas revealed by kernel analysis for density levels which encompassed 50,30 and $10 \%$ of locations of the 2 species. The mean overlap of northern and southern giant petrels at the 3 density levels was $25 \%$; for southern and northern giant petrels the mean overlap was $29 \%$ (Table 3).

Estimated flying speeds were significantly greater for females than for males in both species (Fig. 3a). Estimated total distances covered were greater for females than for males, although differences were only significant for southern giant petrels (Fig. 3b). The maximum foraging range (the furthest point away from the nest) was also substantially greater for females than for males, although the difference was not significant for northern giant petrels and only marginally
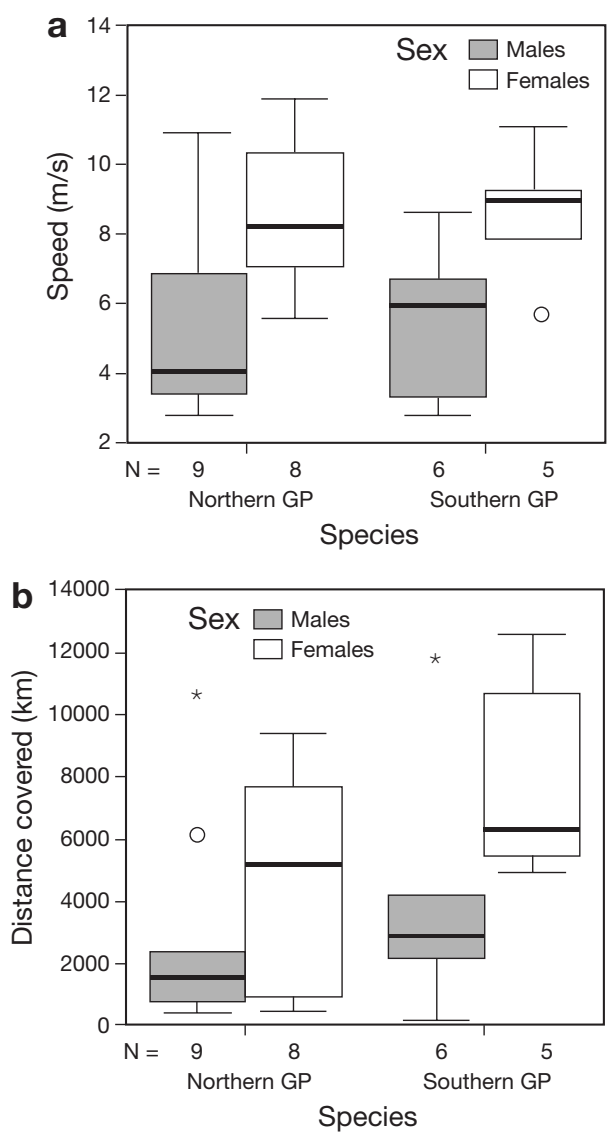

Fig. 3. (a) Estimated median speeds and (b) distances covered during foraging trips by males and females of the northern (NGP) and southern giant petrels (SGP). Differences between sexes were significant for both species for median speed (NGP: Mann-Whitney $U$-test, $Z=-2.31$, p $<0.05$; SGP: $Z=$ $2.00, p<0.05$ ) and significant only for southern giant petrels for distance covered (NGP: Mann-Whitney $U$-test, $Z=-0.8$, $\mathrm{p}=0.44$; SGP: $Z=2.0, \mathrm{p}<0.05$ ). Asterisks are extreme values; circles are outlier values; the length of the box is the interquartile range; the length of the bar is the range, excluding extreme and outlier values. 
significant for southern giant petrels (median of the maximum foraging range for northern giant petrel males: $180 \mathrm{~km}$; range, 127 to 2396; northern giant petrel females: $1226 \mathrm{~km}$; range 950 to 2073; MannWhitney $U$-test, $Z=-1.0, \mathrm{p}=0.29$; southern giant petrel males: $818 \mathrm{~km}$; range, 57 to 2253; southern giant petrel females: $1348 \mathrm{~km}$; range, 942 to 1810; Mann-Whitney $U$-test, $Z=-1.8, \mathrm{p}=0.07$ ).

\section{DISCUSSION}

\section{Resource partitioning}

Males of both species foraged near South Georgia, whereas females made longer and more distant foraging trips at sea. Foraging effort, measured as distance covered and flight velocities of the foraging trips, was clearly greater for females than for males for both species. Differences in foraging areas and foraging efforts for males and females support results of previous observations on diet and on attendance at seal carcasses: during the breeding season, males feed mainly on penguin and seal carcasses on shore while females forage at sea and thus show a higher proportion of krill, squid and fish in their diet (Hunter 1983b, Hunter $\&$ Brooke 1992). Differences in the exploitation of food resources between northern giant petrel males and females also involved important differences in the foraging strategies and are probably related to the sexual size dimorphism in these species (González-Solís et al. 2000). Thus intersexual differences in trophic niche seem greater than interspecific ones. Indeed, similarities in trophic ecology and morphology between sexes of both species suggest that intersexual differences in trophic ecology actually evolved before the speciation of the 2 taxa.

Some observational studies (Johnstone 1974, Weimerskirch et al. 1988, Ballance et al. 1997) on seabird distribution at sea suggest that spatial partitioning while foraging may be a common mechanism to avoid ecological overlap in seabirds. However, in some cases the segregation suggested by observational studies may reflect differences in breeding distributions (observed birds may belong to different populations) or may be confounded by birds of unknown status (e.g. adults, juveniles, breeders and non-breeders can rarely be distinguished at sea) rather than reflecting foraging partitioning of, for instance, populations breeding at the same location. On the other hand, several studies on dietary segregation among congeneric seabird species in the Southern Ocean (e.g. Berruti 1978, Weimerskirch et al. 1986, Ridoux 1994, Croxall et al. 1997) detected substantial interspecific differences in diet composition which were likely to be associated with foraging partitioning. Currently, satellite tracking allows diet composition and spatial partitioning to be studied simultaneously. Recently, Waugh et al. (1999) combined diet sampling and satellite tracking of blackbrowed Diomedea melanophrys and grey-headed $D$. chrysostoma albatrosses breeding at Campbell Island. Interspecific differences in time spent in neritic and oceanic waters were related to differences in the proportion of fish and squid in the diet, showing that foraging partitioning and dietary segregation were associated.

In the case of giant petrels, ship surveys showed that northern giant petrels occur mostly to the north of the APF whereas southern giant petrels are most common to the south, suggesting that the APF may act as an ecological barrier (Bourne \& Warham 1966, Johnstone 1974). At South Georgia this might be the case for females, but not for males. Southern giant petrel females showed an activity range mostly south of the APF and farther east than northern giant petrel females. In contrast, males of both species foraged south of the APF, but there was a sharp spatial segregation between the species, with northern giant petrel males foraging almost exclusively at South Georgia whereas southern giant petrel males foraged farther south and east of South Georgia. This spatial segregation agrees with the observations of lower consumption of Antarctic fur seal carrion by southern giant petrels (Hunter 1983b). Most of the Antarctic fur seal population lives at South Georgia (see below) and the peak abundance of fur seals and pups on beaches is in November and December (Boyd 1989, 1993), creating a simultaneous peak in the availability of dead seals. These 2 months are coincident with the study period and with the period when northern giant petrels seem particularly to scavenge fur seal carcasses (Hunter $1983 b, 1985)$. Thus, the very restricted foraging range of northern giant petrel males at this time is consistent with their strong dependence on fur seal carcasses on South Georgia beaches.

The demonstration of niche differentiation, however, does not explain the processes involved in partitioning, i.e. whether it is an outcome of interspecific competition or not. Spatial segregation of the foraging areas between closely related species breeding sympatrically on subantarctic islands may reflect not only interspecific competition but also the outcome of former allopatric speciation. This may be the case in giant petrels. Observations of birds scavenging fur seal carcasses indicate that southern giant petrels are more successful than northern giant petrels in interspecific disputes (Johnstone 1979), suggesting that southern giant petrels could benefit as much as northern giant petrels from this resource at South Georgia and thus breed similarly early. This apparent contradiction sug- 
gests that ecological segregation between the 2 sibling species may be maintained mostly by differences in foraging area rather than by dietary segregation.

\section{Changes in population size}

South Georgia is an important breeding site for both species of giant petrels. Hunter (1985) estimated that approximately 16 and $29 \%$ of the world breeding populations of southern and northern giant petrels, respectively, occur there. At the beginning of the 1980s, Bird Island was thought to hold about 9 and $52 \%$ of the South Georgia populations of southern and northern giant petrels, respectively (Hunter 1984a). It was suggested then that the southern giant petrel population had remained stable since at least about 1958, whereas northern giant petrels had increased greatly over the same period. Recent population estimates for breeding giant petrels at Bird Island (Table 4) suggest a continuation of those trends over the last 2 decades. The continuing increase in population of northern giant petrels at Bird Island is probably linked to the continued exponential increases in fur seal populations at South Georgia. Elephant and fur seals breed on beaches, and thus, when dead, are readily available for scavenging by giant petrels. Elephant seal carrion, however, is less important than fur seal carrion in the diet of northern giant petrels during the chick-rearing period (Hunter 1983b). Elephant seal carrion is probably important for northern giant petrels during incubation, since southern elephant seals Mirounga leonina are most abundant at South Georgia at the end of October (Boyd et al. 1996). However, fur seal carrion is probably more important than elephant seal carrion, since northern giant petrel energy demands increase during the hatching period in the first week of December, coinciding with peak abundance on beaches of fur seals and pups (Boyd 1989, 1993). Three surveys in the last 4 decades indicate that the southern elephant seal population at South Georgia has not changed significantly in this period, with approximately 110000 breeding females present annually (Boyd et al. 1996). In con-

Table 4. Estimated breeding pairs of northern and southern giant petrels at Bird Island, South Georgia. Data from Hunter (1984a) for the years 1979, 1980 and 1981, and D. R. Briggs \& R. Humpidge (unpubl.) for 1996

\begin{tabular}{|lcc|}
\hline Year & Northern giant petrel & Southern giant petrel \\
\hline 1979 & 1521 & 602 \\
1980 & 1341 & 592 \\
1981 & 1003 & 480 \\
1996 & 2062 & 521 \\
\hline
\end{tabular}

trast, Antarctic fur seals have increased in population consistently over the last 50 yr. Despite being hunted to virtual extinction in the 18th century the fur seal population was rediscovered at South Georgia in the 1930s and has recovered rapidly since the 1950s at an annual rate of increase of between 10 and $17 \%$ (Payne 1977); by 1992, South Georgia was estimated to hold more than 1.5 million Antarctic fur seals (Boyd 1993), and current populations are probably double this number. It is likely that this increase in fur seal population has resulted in enhanced food availability for northern giant petrels over the last $50 \mathrm{yr}$, which may be related to the reported increase of the population. In contrast, breeding populations of southern giant petrel over the last 2 decades have remained essentially stable. This may reflect their less extensive use of seal carrion and more pelagic habits than those of northern giant petrels.

\section{Interactions with longline fisheries}

The foraging areas of the satellite-tracked giant petrels suggests that their distribution at sea overlaps extensively with that of local longline fisheries, which, around South Georgia, are mainly distributed over shelf-slope areas at depths of 1000 to $2000 \mathrm{~m}$ (see Croxall \& Prince 1996, Prince et al. 1998). Giant petrels are attracted to vessels and are well known for following longline fishing vessels (Ashford et al. 1995, Cherel \& Weimerskirch 1996, Barnes et al. 1997), making them highly susceptible to accidental capture on longline hooks. Direct evidence of mortality of giant petrels from Bird Island associated with fishery activities comes from analyses of death circumstances and recent direct observations. From 133 rings recovered from dead giant petrels with known circumstances of death, Hunter (1984b) indicated that $12(9 \%)$ were reported as resulting from fishing, comprising 3 caught in nets and 9 caught on fishing lines. These numbers and percentages are clearly minima, since fishermen rarely report birds killed whilst fishing. Since Hunter's (1984b) study, longline fisheries for Patagonian toothfish Dissostichus eleginoides have increased substantially in the South Atlantic Ocean, especially around southern South America, the Falkland Islands and South Georgia (Croxall \& Prince 1996, Prince et al. 1998). In these areas, reports from scientific observers on licenced fishing vessels indicate that giant petrels are the third most common species caught, after blackbrowed albatrosses Diomedea melanophris and whitechinned petrels Procellaria aequinoctialis (Ashford et al. 1995, CCAMLR 1996, 1997, 1998). When giant petrels were recorded, southern giant petrels outnumbered northern giant petrels by 2 to 1 (e.g. CCAMLR 
1997). This accords well with the more pelagic habits of the former species. Giant petrel females seem to be at the highest risk of being caught accidentally on longline hooks because of their larger activity ranges and longer foraging trips; northern giant petrel females show the greatest overlap between their foraging areas and the main areas of longline fishing in the region.

\section{Conclusions}

For these 2 sibling species of giant petrel, within their area of breeding sympatry, foraging ranges at sea are strongly segregated spatially between species as well as between sexes. Thus, although southern giant petrels forage further south than northern giant petrels, males of both species (but particularly the northern giant petrel) forage mainly close inshore, relating to their feeding on seal and penguin carcasses. Females of both species foraged offshore, which relates to capture of live marine prey and scavenging at vessels. The foraging ranges of females, even while breeding, are much greater than previously realised, regularly traversing the $\mathrm{APF}$, which clearly does not function as a constraint or barrier, as previously suggested. The ability to exploit inshore as well as offshore habitats and versatility to exploit live prey and carrion predisposes both species, but especially females, towards interactions with existing or potential anthropogenic threats, ranging from longline vessels to inshore pollutants.

Acknowledgements. This study was partially funded by the Training and Mobility Programme of the European Commission (ERBFMBICT983030), the Dirección General de Investigación Científica del Ministerio de Educación y Ciencia Español (PF960037747439), the British Antarctic Survey and the Universitat de Barcelona. We thank the team at Bird Island, especially Chris Hill, for invaluable help in the field, and Dirk Briggs for logistic support. Pete Prince, who died at the beginning of the project, made this study possible with his initial support. We thank Dirk Briggs and Richard Humpidge for the use of their unpublished data and Eugene Murphy for sourcing the information on the position of the APF.

\section{LITERATURE CITED}

Ashford JR, Croxall JP, Rubilar PS, Moreno CA (1995) Seabird interactions with long-lining operations for Dissostichus eleginoides around South Georgia, April to May 1994. CCAMLR Science 2:111-122

Ashmole NP, Ashmole MJ (1967) Comparative feeding ecology of sea birds of a tropical oceanic island. Peabody Mus Nat Hist Yale Univ Bull 24

Ballance LT, Pitman RL, Reilly SB (1997) Seabird community structure along a productivity gradient: importance of competition and energetic constraint. Ecology 78:1502-1518
Barnes KN, Ryan PG, Boix-Hinzen C (1997) The impact of hake Merluccius spp. longline fishery off South Africa on Procellariiform seabirds. Biol Conserv 82:227-234

Berruti A (1978) The breeding biology of sooty albatrosses Phoebetria fusca and P. palpebrata. Emu 79:161-175

Bourne WRP, Warham J (1966) Geographical variation in the giant petrels of the genus Macronectes. Ardea 54:45-67

Boyd IL (1989) Spatial and temporal distribution of Antarctic fur seals (Arctocephalus gazella) on the breeding grounds at Bird Island, South Georgia. Polar Biol 10:179-185

Boyd IL (1993) Pup production and distribution of breeding Antarctic fur seals (Arctocephalus gazella) at South Georgia. Antarct Sci 5:17-24

Boyd IL, Walker TR, Poncet J (1996) Status of southern elephant seals at South Georgia. Antarct Sci 8:237-244

Brothers N, Gales R, Hedd A, Robertson G (1998) Foraging movements of the shy albatross Diomedea cauta breeding in Australia: implications for interaction with longline fisheries. Ibis 140:446-457

Burger AE (1978) Interspecific breeding attempts by Macronectes giganteus and M. halli. Emu 78:234-235

CCAMLR (Commission for the Conservation of Antarctic Marine Living Resources) (1996) Report of the fifteenth meeting of the Scientific Committee. CCAMLR, Hobart

CCAMLR (1997) Report of the sixteenth meeting of the Scientific Committee. CCAMLR, Hobart

CCAMLR (1998) Report of the seventeenth meeting of the Scientific Committee. CCAMLR, Hobart

Cherel Y, Weimerskirch H (1996) Interactions between longline vessels and seabirds in Kerguelen waters and a method to reduce seabird mortality. Biol Conserv 75:63-70

Croxall JP, Prince PA (1980) Food, feeding ecology and ecological segregation of seabirds at South Georgia. Biol J Linn Soc 14:103-131

Croxall JP, Prince PA (1996) Potential interactions between wandering albatrosses and longline fisheries for Patagonian Toothfish at South Georgia. CCAMLR Science 3:101-110

Croxall JP, Rothery P, Pickering SPC, Prince PA (1990) Reproductive performance, recruitment and survival of wandering albatrosses Diomedea exulans at Bird Island, South Georgia. J Anim Ecol 59:775-796

Croxall JP, Prince PA, Reid K (1997) Dietary segregation of krill-eating South Georgia seabirds. J Zool 242:531-556

de la Mare WK, Kerry KR (1994) Population dynamics of the wandering albatross (Diomedea exulans) on Macquarie Island and the effects of mortality from longline fishing. Polar Biol 14:231-241

De Solla S, Bonduriansky R, Brooks RJ (1999) Eliminating autocorrelation reduces biological relevant of home range estimates. J Anim Ecol 68:221-234

Diamond AW (1983) Feeding overlap in some tropical and temperate seabird communities. Stud Avian Biol 8:24-46

González-Solís J, Croxall JP, Wood AG (2000) Sexual dimorphism and sexual segregation in foraging strategies of northern giant petrels Macronectes halli during the incubation period. Oikos 90:390-398

Hunter S (1983a) Interspecific breeding in giant petrels at South Georgia. Emu 82 (Suppl):312-314

Hunter S (1983b) The food and feeding of the giant petrels Macronectes halli and M. giganteus at South Georgia. J Zool 200:521-538

Hunter S (1984a) Breeding biology and population dynamics of giant petrels Macronectes at South Georgia (Aves: Procellariiformes). J Zool 203:441-460

Hunter S (1984b) Movements of giant petrels Macronectes spp. ringed at South Georgia. Ring Migrat 5:105-112 
Hunter S (1985) The role of giant petrels in the Southern Ocean ecosystem. In: Siegfried WR, Condy PR (eds) Antarctic nutrient cycles and food webs. Springer-Verlag, Berlin, p 534-542

Hunter S (1987) Species and sexual isolation mechanisms in sibling species of giant petrels Macronectes. Polar Biol 7:295-301

Hunter S, Brooke ML (1992) The diet of giant petrels Macronectes spp. at Marion Island, Southern Indian Ocean. Colon Waterbirds 15:56-65

Johnstone GW (1974) Field characterters and behaviour at sea of giant petrels in relation to their oceanic distribution. Emu 74:209-218

Johnstone GW (1978) Interbreeding by Macronectes halli and M. giganteus at Macquarie Island. Emu 78:235

Johnstone GW (1979) Agonistic behaviour of the giant-petrels Macronectes giganteus and M. halli feeding at seal carcasses. Emu 79:129-132

Jouventin P, Weimerskirch H (1990) Satellite tracking of wandering albatrosses. Nature 343:746-748

Moore JK, Abbot MR, Richman JG (1999) Location and dynamics of the Antarctic Polar Front from satellite sea surface temperature data. J Geophys Res 104:3059-3073

Parmelee DF, Parmelee JM, Fuller MR (1985) Ornithological investigations at Palmer Station: the first long-distance tracking of seabirds by satellites. Antarct J US 20:162-163

Payne MR (1977) Growth of a fur seal population. Phil Trans R Soc Lond B 279:67-79

Prince PA, Wood AG, Barton T, Croxall JP (1992) Satellite tracking of wandering albatrosses (Diomedea exulans) in the South Atlantic. Antarct Sci 4:31-36

Prince PA, Croxall JP, Trathan PN, Wood AG (1998) The pelagic distribution of South Georgia albatrosses and their relationships with fisheries. In: Robertson G, Gales R (eds) Albatross biology and conservation. Surrey Beatty \& Sons, Chipping Norton, p 137-167

Ridoux V (1994) The diets and dietary segregation of seabirds at the subantarctic Crozet Island. Mar Ornithol 22:1-192

Rodhouse PG, Prince PA, Trathan PN, Hatfield EMC, Watkins JL, Bone DG, Murphy EJ, White MG (1996) Cephalopod community associated with mesoscale oceanographic features at the Antarctic Polar Front: use of satellite-tracked avian predators to locate pelagic food web activity. Mar Ecol Prog Ser 136:37-50

Rootes DM (1988) The status of birds at Signy Island, South Orkney Islands. Br Antarct Surv Bull 80:87-119

SCAR (Scientific Committee on Antarctic Research) (1992) Status and trends of Antarctic and Sub-Antarctic seabirds. Report of the Eleventh Meeting of the Scientific Committee of CCAMLR. CCAMLR, Hobart, p 443-461

Schoener TW (1974) The compression hypothesis and temporal resource partitioning. Proc Natl Acad Sci USA 71: 4169-4172

Editorial responsibility: Otto Kinne (Editor), Oldendorf/Luhe, Germany
Spear L, Ainley DG (1998) Morphological differences relative to ecological segregation in petrels (Family: Procellariidae) of the Southern Ocean and tropical Pacific. Auk 115:1017-1033

Strikwerda TE, Fuller MR, Seegar WS, Howey PW, Black HD (1986) Bird-borne satellite transmitter and location program. Johns Hopkins APL Tech Dig 7:203-208

Warham J (1990) The petrels: their ecology and breeding systems. Academic Press, London

Waugh SM, Weimerskirch, Cherel Y, Shankar U, Prince PA, Sagar PM (1999) Exploitation of the marine environment by two sympatric albatrosses in the Pacific Southern Ocean. Mar Ecol Prog Ser 177:243-254

Weimerskirch H (1995) Regulation of foraging trips and incubation routine in male and female wandering albatrosses. Oecologia 102:37-43

Weimerskirch H, Jouventin P, Stahl J (1986) Comparative feeding ecology of the six albatross species breeding on the Crozet Islands. Ibis 128:195-213

Weimerskirch H, Bartle J, Jouventin P, Stahl J (1988) Foraging ranges and partitioning of feeding zones in three species of southern albatrosses. Condor 90:214-219

Weimerskirch H, Doncaster C, Cuenot-Chaillet F (1994) Pelagic seabirds and the marine environment: foraging patterns of wandering albatrosses in relation to prey availability and distribution. Proc R Soc Lond 255:91-97

Weimerskirch H, Cherel Y, Cuenot-Chaillet F, Ridoux V (1997a) Alternative foraging strategies and resources allocation by male and female wandering albatrosses. Ecology 78:2051-2063

Weimerskirch H, Brothers N, Jouventin P (1997b) Population dynamics of Wandering Albatross Diomedea exulans and Amsterdam Albatross D. amsterdamensis in the Indian Ocean and their relationships with long-line fisheries: conservation implications. Biol Conserv 79:257-270

Weimerskirch H, Catard A, Prince PA, Cherel Y, Croxall JP (1999) Foraging white-chinned petrels Procellaria aequinoctialis at risk from the tropics to Antarctica. Biol Conserv 87:273-275

Wilson RP, Wilson MT (1989) Tape: a package-attachment technique for penguins. Wildl Soc Bull 17:77-79

Woehler EJ, Croxall JP (1997) The status and trends of Antarctic and sub-Antarctic seabirds. Mar Ornithol 25: 43-66

Woehler EJ, Johnstone GW (1991) Status and conservation of the seabirds of the Australian Antarctic Territory. In: Croxall JP (ed) Seabird status and conservation: a supplement. International Council for Bird Preservation, Cambridge, p 279-308

Wood AG, Naef-Daenzer B, Prince PA, Croxall JP (2000) Quantifying habitat use in satellite-tracked pelagic seabirds: application of kernel estimation to albatross locations. J Avian Biol (in press)

Submitted: September 22, 1999; Accepted: March 21, 2000

Proofs received from author(s): September 12, 2000 